\title{
Detection errors on the word the: Evidence for the acquisition of reading levels
}

\author{
ADAM DREWNOWSKI \\ The Rockefeller University, New York, New York 10021
}

\begin{abstract}
The pattern of detection errors on the word the made by groups of school children and adults searching four 25-word passages for instances of the target letter $t$ was found to depend on the subjects' reading ability as well as on the orthographic, syntactic, and semantic constraints of the search passages. The conditional percentage of errors on the word the made by children reading at first-grade level was no different from that expected on the basis of chance for any of the four passages. Disproportionately more errors on the were made on the prose and scrambled-word passages by children reading at second-grade level and above and by adults, with the difference between the prose and scrambled-word passages being significant only for the most fluent readers. These results are consistent with a multilevel model of reading, and are taken to support the hypothesis that reading-processing skills at various levels are acquired at different rates.
\end{abstract}

It is generally agreed that reading involves the use of processing skills occurring at various levels of analysis (Gibson, 1971: LaBerge \& Samuels, 1974; Smith, 1971, 1973). Specifically, reading may involve separately attending to the graphological features of letters, the orthographic regularities of letter sequences, the phonological features of letters, and the semantic and syntactic properties of words and word groups (Gibson, 1971). However, because of a relative lack of studies monitoring performance on reading-related skills through the years of reading acquisition (Doehring, 1976; Mohan, 1978), very little is known about the way in which these processing levels are acquired in learning to read. The present study traces the temporal development of reading-processing skills in different groups of school children and adults in order to test the hypothesis that such skills are leamed at different rates, with graphological and orthographic skills being the first to be acquired, and with processing in terms of syntactic features such as phrase structure not becoming functional until several years later (Doehring, 1976).

Using earlier work on the pattern of detection errors on the word the (Drewnowski \& Healy, 1977; Healy, 1976) as its basis, the present study employs a letterdetection task to determine the highest level of processing that is available to a given group of subjects when they are reading printed text. In addition to

This research was supported in part by National Science Foundation Grant GB 41176 and National Institute of Mental Health Grant MH 23878 to the Rockefeller University. I am indebted to the principal and the staff of Public School 183 for their assistance in carrying out the experiments reported here, and to W. K. Estes, A. F. Healy, and C. Lee for helpful discussions about this research. Requests for reprints should be sent to Adam Drewnowski, now at the Department of Psychology, University of Toronto, Toronto, Ontario, Canada M5S 1A1. manipulating the orthographic, syntactic, and semantic constraints of the passage that is being searched for instances of the target letter, the present study independently varies the level of the subjects' reading skill. Changes in the pattern of detection errors on the word the with changes in the syntactic-semantic constraints of the search passages are expected to reflect the highest level of processing that is being employed for a given type of printed text; changes in the pattern of detection errors with changes in the level of the subjects' reading skill are expected to reflect the highest level of processing that is attained by subjects at a given stage of reading acquisition.

The letter-detection task employed in the present study was selected following earlier observations that subjects searching for instances of a given target letter in printed text make a disproportionate number of errors on the word the (Corcoran, 1966; Healy, 1976). The target letter $t$ in the word the is thus far more likely to be missed than the letter $t$ in any other target word (e.g., thesis). Healy (1976) found the high frequency of occurrence in the language of the word the to be critical, and suggested that highly frequent words are read in terms of units larger than the letter. Drewnowski and Healy (1977), using words and letters as targets, found that a disproportionate number of errors is made on the words the and and whenever they appear in an appropriate syntactic context, that is, as part of a familiar phrase. These data were interpreted by Drewnowski and Healy as supporting a specific set of hypotheses pertaining to a model of the reading process. In common with other investigators (Gibson, 1971), Drewnowski and Healy assumed that reading involves a hierarchy of processing levels, defined in terms of the units available at each level: letters, letter groups, words, phrases, or larger units such as clauses or sentences. 
Subjects were assumed to form internal representations of text in parallel at the various levels available to them. Higher order units could then be completely processed to the point of yielding their meaning before all of their constituents were fully identified, such that the subject could move to the next unit of text at that level without necessarily completing the processing of units at lower levels. Because the availability of higher order units was specifically assumed to depend upon the semantic and syntactic constraints of the search passage, the subjects' performance on the detection task was expected to be influenced by the type of passage being searched, with more letter-detection errors being made whenever higher order units became available. Increasing the orthographic and syntactic-semantic constraints of the search passage in going from scrambled-letter to prose passages was therefore expected to result in a larger proportion of letter-detection errors on the word the, as was the case.

The search passages used here resemble those previously employed by Drewnowski and Healy (1977). The "words" of the scrambled-letter passage are meaningless (and mostly unpronounceable) letter strings, with the highest available level of processing presumed to be the letter or the letter-group level. Scrambled-word passages consist of randomly permuted words, with the highest available level of processing accordingly presumed to be the word or the word-group level. The highest level of processing employed with the meaningful prose passage is presumed to be the phrase level or higher. In an additional list passage, the usual left-to-right reading pattern is altered by presenting the words in the form of vertical lists. This procedure is thought to impede phrase-level processing, with the highest available level of processing presumed to be the level of the word.

The hypotheses put forward by Drewnowski and Healy (1977) lead one to expect that the highest available level of processing for a particular type of text (and therefore the conditional error performance scores on the word the) will be determined by the structure of the search passage and by the subjects' attained degree of reading skill. Because the subjects in the Drewnowski and Healy (1977) and Healy (1976) studies were collegeage adults, it was naturally assumed that all were fluent readers and that the structure of the search passage was therefore limiting. However, the proportion of letter-detection errors in prose passages has also been shown to be a function of school grade, and thus, presumably, of reading skill (Mohan, 1978). And because the attained degree of reading skill is independently varied in the present study, changes in the pattern of detection errors on the word the might be expected to serve as a measure of the course of acquisition of reading-processing levels in learning to read.

Specifically, one might expect the conditional error percentages to indicate whether the highest level of internal representation of text that is available to a giver group of subjects is above or below that permitted by the structure of the search passage. Children reading at letter level would therefore be expected to be insensitive to passage structure, showing conditiona error percentages at or near chance level on the scrambled-letter, scrambled-word, and prose passages Children reading at word level would be expected tc show higher conditional error percentages for the prose and the scrambled-word passages than for the scrambled letter passage. Only fully functional phrase-level reading would be expected to lead to significant differences in conditional error percentages between the scrambled. word and the prose passage, with significantly more detection errors occurring on the word the placed in its appropriate syntactic context in the prose passage.

\section{METHOD}

\section{Subjects}

Children from Public School 183 in Manhattan (Grades 1-5) served as subjects in group experiments conducted in the classroom. The total sample included 50 children in Grade 1, 47 children in Grade 2, 44 children in Grade 3,53 children in Grade 4, and 50 children in Grade 5. Because the test was administered on two separate occasions, exactly 1 year apart, 31 out of the 49 first graders were tested twice: once in the first and once in the second grade. An additional group of 47 young adults was recruited from among subjects participating in other experiments in the Mathematical Psychology Laboratory at the Rockefeller University. These subjects were tested individually.

In order to separate the effects of reading level from those of school grade, children in Grades 1 and 5 were divided into approximately equal groups of good and poor readers. The reading ability of first-grade children was inferred from the teachers' evaluations, and in some cases from the Stanford Early Achievement test. The reading ability of the remaining children was established by the New York City Testing Program, administered in each case some weeks prior to the present experiment. The mean Reading Grade Equivalent (RGE) of poor readers in the first grade $(\mathrm{N}=25)$ was 1.0 ; that of good readers $(\mathrm{N}=25)$ was 2.0 . The mean $\mathrm{RGE}$ for poor readers in the fifth grade $(\mathrm{N}=26)$ was 4.2 (fourth grade, second month), whereas that for good readers in the fifth grade $(\mathrm{N}=22)$ was 7.8 (seventh grade, eighth month).

\section{Stimulus Materials}

Four 25-word passages, typed on separate sheets of paper, were constructed for the present experiment. (See the Appendix for copies of the four passages.) One passage, composed of three simple sentences and hereafter referred to as the "prose passage," contained four instances of the word the, eight instances of target words containing the trigram the, but no other instance of the letter $t$ (mother, clothes, other, their, then, brother, lather, there), and 13 filler words selected with the restriction that no word include the letter $t$. Every instance of the letter $t$ in the passage was therefore part of the letter string the.

The second passage, hereafter referred to as the "scrambledword passage," was derived from the prose passage. The four thes and the eight target words were in the same locations as in the prose passage, and the overall punctuation remained the same. The order of the filler words was random, with the constraint that the word the was never followed by a noun. The present scrambled-word passage thus resembles the nocontext scrambled-word passage used by Drewnowski and 
Healy (1977, Experiment 2), rather than the scrambled-word passage of Drewnowski and Healy (1977, Experiment 1), in which six instances of the preceded and six did not precede a noun, or a former passage of Healy (1976, Experiment 2), in which the context of the word the was totally unconstrained.

The third passage, hereafter referred to as the "scrambledletter passage," was also derived from the prose passage. All $t \mathrm{~s}$ were kept in the same locations and "interword" spaces were kept constant, but locations of the other letters were randomized within each five-word string.

The fourth passage, referred to as the "list," was derived from the scrambled-word passage. The sequence of words was preserved, but they were typed flush left in four vertical columns. Punctuation was eliminated.

The four passages were stapled together into a booklet. Multiples of the 24 possible order permutations were employed, so that the presentation order of the passages would be roughly counterbalanced across subjects. Since the number of subjects varied from 44 in Grade 3 to 53 in Grade 4 , the presentation order could not be counterbalanced perfectly. In order to insure that the children attempted to read at least the prose passage for meaning, a fifth page at the back of each booklet contained a single question referring to the prose passage.

\section{Procedure}

All school children were given verbal instructions to read each passage in turn and to circle every instance of the letter $t$. They were told that only one passage made sense while the rest did not, and that a question on the last page would refer to the content of the prose passage, and that they should try to answer it if they could.

Adult subjects tested in the laboratory were given written instructions to the same effect. In addition to the reading and circling task, they were asked to measure their reading times with a stopwatch.

\section{Scoring}

Although the letter-detection task employed both here and by Drewnowski and Healy (1977) was similar to the visual search tasks used by both Doehring (1976) and by Gibson (1971), the critical dependent variable in the present study was not the relatively insensitive measure of scanning rate used by Doehring (1976), but rather the conditional percentage of omission errors in the locations given an error. An error in a the location was defined as an omission of a $t$ in the word the in the prose, scrambled-word, and list passages, or in the corresponding nonword location in the scrambled-letter passage. Because 4 out of 12 instances of the target letter $t$ in each passage occur in the locations, the conditional percentage of errors at those locations, expected purely on the basis of chance, would be $33 \%$. The conditional error percentages for a given subject were derived by determining the ratio of the number of errors in the locations to the total number of errors, and mean conditional error percentages were obtained by averaging across subjects.

\section{RESULTS}

\section{Effects of School Grade}

Mean conditional percentages for errors in the locations for the four search passages are shown in Figure 1, separately for children in each school grade and for adults.

The observed pattern of detection errors in the locations was a function of passage type and of the subjects' school grade. A two-way analysis of variance of conditional error percentages showed significant

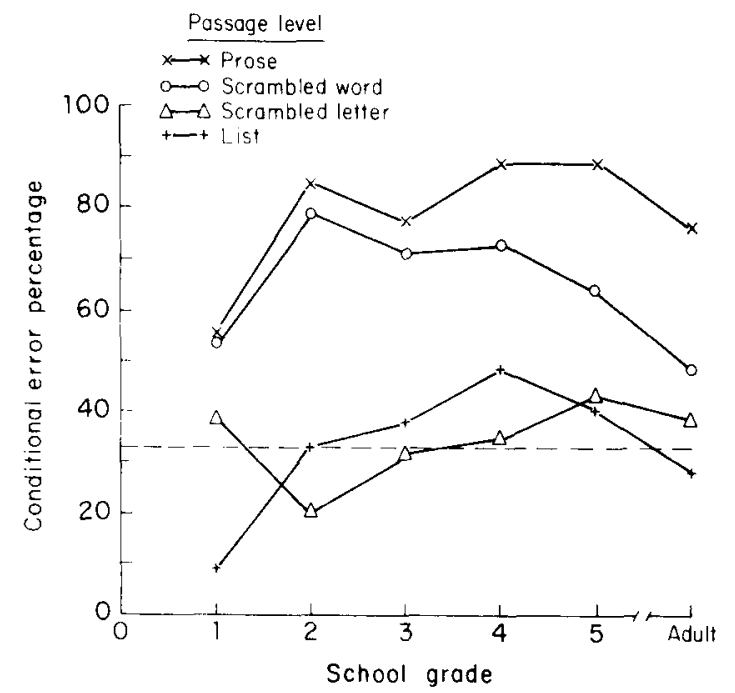

Figure 1. Conditional percentages of errors in the locations given an error as a function of school grade and passage level. The expected chance level of $33 \%$ is indicated by the broken line.

main effects of passage type $[F(3,533)=38.83$, $\mathrm{p}<.001]$ and school grade $[\mathrm{F}(5,533)=3.51, \mathrm{p}<.01]$, but no Passage Type by School Grade interaction $[F(15,533)=1.25$, n.s. $]$.

The subjects' conditional error performance on the word the on the scrambled-letter and the list passages did not vary as a function of the subjects' reading ability: The conditional error percentages were consistently at chance level (indicated in Figure 1 by the broken line), except for first-grade children's performing significantly below chance level on the list passage $[t(22)=8.30, p<.01]$. In contrast, the percentages of detection errors on the word the on the prose and scrambled-word passages were significantly above chance level and also varied with school grade. There were significant differences in conditional error percentages between first- and second-grade school children on both the prose [planned-comparison $t$ test: $t(55)=3.09, p<.01]$ and scrambled-word passages $[\mathrm{t}(52)=2.61, \mathrm{p}<.01]$, indicating that second graders made proportionally more detection errors on the word the. Furthermore, the difference in conditional error percentages on the word the between the prose and scrambled-word passages, which is assumed to reflect the subjects' sensitivity to the syntactic-semantic constraints of the search passage, was significant only for children in school Grades 4 [ $t(66)=2.04, p<.05]$ and $5[\mathrm{t}(59)=3.23, \mathrm{p}<.01]$, and for the young adults $[\mathrm{t}(57)=2.80, \mathrm{p}<.01]$.

The pattern of the adults' performance on the four passages used confirms the earlier results of Drewnowski and Healy (1977). The conditional error percentage for the prose passage $(76 \%)$ was significantly above chance level $[\mathrm{t}(31)=8.60, \mathrm{p}<.01]$ and above that obtained for the scrambled-word passage $[\mathrm{t}(57)=2.96$, 
$p<.01]$. The conditional error percentage for the scrambled-word passage $(48 \%)$ was not significantly above chance level $[t(26)=1.87$, n.s.], in agreement with the results reported by Drewnowski and Healy (1977, Experiment 2). The conditional error percentages for the scrambled-letter and list passages were also not significantly different from chance level.

Further analyses demonstrate how the systematic variations with school grade in the pattern of detection errors on the word the are reflected in the overall error scores for each of the four passages. The subjects' total error scores and their scores on target words other than the are shown in Table 1, which includes the means and the standard errors of the means for the four passages and the six groups of subjects. The means and standard errors were derived by computing the total number of errors on each passage and the number of errors in locations other than the for each subject, and then averaging across subjects.

Total error scores show that all subjects except those in the first grade were considerably more accurate on the scrambled-letter and the list passages than on the scrambled-word or prose passages, and there was a significant main effect of passage type $[F(3,1136)=25.27, p<.001]$. Older subjects were also more accurate on the letter-detection task than were younger subjects. The main effect of school grade $[F(5,1136)=10.71, p<.01]$ was also significant, and there was no Passage Type by School Grade interaction $[F(15,1136)=1.45$, n.s. $]$.

Changes in the conditional error performance with passage type appeared to be entirely due to the changing proportion of errors on the word the. A corresponding analysis of errors made on non-the targets showed significant effects of school grade $[F(5,1136)=14.87$, $\mathrm{p}<.01]$, again indicating an increase in accuracy with age, but no significant effect of passage type $[F(3,1136)=1.62$, n.s. $]$, and no Passage Type by School Grade interaction $[F(15,1136)=.95$, n.s. $]$. The proportion of errors made on non-the targets was therefore independent of passage structure. Furthermore, the increase in conditional error percentages observed between the first and second grades was associated with fewer errors made on the non-the targets. Thus, whereas the proportion of errors on the word the increased with age, leading to higher conditional error percentages on the prose and scrambled-word passages, the proportion of errors on non-the targets actually decreased with increasing age.

The present pattern of errors on the word the cannot be explained by the notion of a speed-accuracy tradeoff, since the conditional error percentages did not appear to be influenced by the total error scores. It is equally unlikely that the present pattern of results was due to the children's inability to identify the target letter $t$, since all subjects were very accurate on the scrambledletter, and particularly on the list passages. Rather, the specific differences in conditional error percentages with school grade appear to be a consequence of different reading strategies, assumed here to be determined by the structure of the search passage and by the subjects' attained level of reading skill.

\section{Effects of Reading Grade}

In the above analyses, the children's school grade was taken as an index of the children's reading ability. It is now necessary to demonstrate that the present pattern of results is a direct consequence of reading ability rather than of school grade level. This was done by holding school grade constant and dividing the children within each of the school Grades 1 and 5 into approximately equal groups of good and poor readers.

Data shown in Table 2 include the means and the standard errors of the means for the conditional percentages of errors in the locations given an error. Higher conditional error percentages were obtained by fifth graders than by first graders, by good readers than by poor readers, and on the prose and scrambledword passages than on the scrambled-letter and the list passages.

A three-way analysis of variance, with school grade, passage type, and reading level as the main variables, showed significant main effects of school

Table 1

Means and Standard Errors for the Total Number of Errors (TE) and the Number of Errors in Locations Other Than the (non-the Errors, NTE)

\begin{tabular}{|c|c|c|c|c|c|c|c|c|c|c|c|c|c|c|c|c|c|}
\hline \multirow{4}{*}{$\begin{array}{l}\text { School } \\
\text { Grade }\end{array}$} & \multirow{4}{*}{$\mathrm{N}$} & \multicolumn{16}{|c|}{ Passage Type } \\
\hline & & \multicolumn{4}{|c|}{ Prose } & \multicolumn{4}{|c|}{ Scrambled Word } & \multicolumn{4}{|c|}{ Scrambled Letter } & \multicolumn{4}{|c|}{ List } \\
\hline & & \multicolumn{2}{|c|}{ TE } & \multicolumn{2}{|c|}{ NTE } & \multicolumn{2}{|c|}{$\mathrm{TE}$} & \multicolumn{2}{|c|}{ NTE } & \multicolumn{2}{|c|}{ TE } & \multicolumn{2}{|c|}{ NTE } & \multicolumn{2}{|c|}{$\mathrm{TE}$} & \multicolumn{2}{|c|}{ NTE } \\
\hline & & Mean & SE & Mean & SE & Mean & SE & Mean & SE & Mean & SE & Mean & SE & Mean & SE & Mean & $\mathrm{SE}$ \\
\hline 1 & 50 & 1.90 & .28 & 1.14 & .24 & 1.42 & .25 & .90 & .23 & 1.78 & .32 & 1.24 & .24 & 1.42 & .30 & 1.24 & .25 \\
\hline 2 & 47 & 1.21 & .21 & .32 & .13 & .91 & .18 & .28 & .12 & .85 & .18 & .68 & .16 & .15 & .11 & .12 & .10 \\
\hline 3 & 44 & 2.16 & .29 & .77 & .20 & 1.84 & .30 & .84 & .24 & 1.07 & .26 & .70 & .20 & .59 & .23 & .45 & .20 \\
\hline 4 & 53 & 1.39 & .17 & .28 & .13 & 1.34 & .23 & .50 & .15 & .75 & .15 & .53 & .13 & .36 & .13 & .22 & .10 \\
\hline 5 & 49 & 1.28 & .21 & .32 & .14 & 1.30 & .19 & .53 & .12 & .61 & .15 & .32 & .08 & .32 & .13 & .20 & .07 \\
\hline Adults & 47 & 1.44 & .18 & .40 & .09 & 1.00 & .16 & .55 & .12 & .38 & .11 & .23 & .08 & .55 & .14 & .32 & .08 \\
\hline
\end{tabular}


Table 2

Means and Standard Errors for Conditional Percentages of Errors in the Locations Given an Error

\begin{tabular}{|c|c|c|c|c|c|c|c|c|c|c|c|c|c|c|c|}
\hline \multirow{4}{*}{$\begin{array}{l}\text { School } \\
\text { Grade }\end{array}$} & \multirow{4}{*}{$\begin{array}{c}\text { Reading } \\
\text { Level }\end{array}$} & \multirow{4}{*}{$\begin{array}{l}\text { Mean } \\
\text { RGE }\end{array}$} & \multirow[b]{4}{*}{$\mathrm{N}$} & \multicolumn{12}{|c|}{ Passage Type } \\
\hline & & & & \multicolumn{3}{|c|}{ Prose } & \multicolumn{3}{|c|}{ Scrambled Word } & \multicolumn{3}{|c|}{ Scrambled Letter } & \multicolumn{3}{|c|}{ List } \\
\hline & & & & \multicolumn{2}{|c|}{ Percent } & \multirow[b]{2}{*}{$\mathbf{N}^{\prime}$} & \multicolumn{2}{|c|}{ Percent } & \multirow[b]{2}{*}{$\mathrm{N}^{\prime}$} & \multicolumn{2}{|c|}{ Percent } & \multirow[b]{2}{*}{$\mathbf{N}^{\prime}$} & \multicolumn{2}{|c|}{ Percent } & \multirow[b]{2}{*}{$\mathrm{N}^{\prime}$} \\
\hline & & & & Mean & $\mathrm{SE}$ & & Mean & $\mathrm{SE}$ & & Mean & SE & & Mean & SE & \\
\hline 1 & $\begin{array}{l}\text { Poor } \\
\text { Good }\end{array}$ & $\begin{array}{l}1.0 \\
2.0\end{array}$ & $\begin{array}{l}25 \\
25\end{array}$ & $\begin{array}{l}40 \\
79\end{array}$ & $\begin{array}{l}8 \\
9\end{array}$ & $\begin{array}{l}19 \\
12\end{array}$ & $\begin{array}{l}36 \\
79\end{array}$ & $\begin{array}{r}9 \\
11\end{array}$ & $\begin{array}{l}17 \\
12\end{array}$ & $\begin{array}{l}28 \\
49\end{array}$ & $\begin{array}{r}8 \\
11\end{array}$ & $\begin{array}{l}16 \\
15\end{array}$ & $\begin{array}{r}11 \\
3\end{array}$ & $\begin{array}{l}4 \\
3\end{array}$ & $\begin{array}{r}15 \\
8\end{array}$ \\
\hline 5 & $\begin{array}{l}\text { Poor } \\
\text { Good }\end{array}$ & $\begin{array}{l}4.2 \\
7.8\end{array}$ & $\begin{array}{l}22 \\
21\end{array}$ & $\begin{array}{l}78 \\
97\end{array}$ & $\begin{array}{l}8 \\
3\end{array}$ & $\begin{array}{l}14 \\
13\end{array}$ & $\begin{array}{l}55 \\
73\end{array}$ & $\begin{array}{r}10 \\
9\end{array}$ & $\begin{array}{l}13 \\
13\end{array}$ & $\begin{array}{l}65 \\
38\end{array}$ & $\begin{array}{l}11 \\
18\end{array}$ & $\begin{array}{l}6 \\
7\end{array}$ & $\begin{array}{l}48 \\
33\end{array}$ & $\begin{array}{l}22 \\
33\end{array}$ & $\begin{array}{l}5 \\
3 \\
\end{array}$ \\
\hline
\end{tabular}

Note-The total number of subjects (N) does not necessarily equal the number of subjects on which the mean conditional error percentages are based $\left(N^{*}\right)$, since not all subjects made errors on each passage.

grade $[F(1,172)=12.31, p<.01]$ and passage type $[F(1,172)=14.11, p<.01]$, as well as the Passage Type by Reading Level $[\mathrm{F}(3,172)=3.58, \mathrm{p}<.05]$ and Reading Level by School Grade $[F(1,172)=4.69$, $\mathrm{p}<.01]$ interactions.

The conditional error percentages for the poor readers in the first grade were not significantly different from chance level for the prose, scrambled-word, and scrambled-letter passages, and were significantly below chance level for the list passage $[\mathrm{t}(14)=11.00, \mathrm{p}<.01]$. In contrast, the conditional error percentages for the good readers were significantly above chance level for both the prose $[\mathrm{t}(11)=5.07, \mathrm{p}<.01]$ and scrambledword $[\mathrm{t}(11)=4.15, \mathrm{p}<.01]$ passages, indicating that a disproportionate number of errors was made on the word the in these passages.

Good and poor readers in the first grade thus differed significantly in terms of their performance on the prose $[t(29)=3.05, p<.01]$ and the scrambled-word passages $[t(27)=2.98, p<.01]$, but not on the scrambledletter passage $[\mathrm{t}(29)=1.68$, n.s. $]$ or the list passage $[\mathrm{t}(21)=.53$, n.s. $]$.

These data show that the above-chance conditional error percentages obtained for the prose and scrambledword passages by first-grade children were entirely due to good readers. Even the good readers, however, did not show a significant difference in conditional error percentages between the prose and the scrambled-word passages $[\mathrm{t}(22)=0.00$, n.s. $]$. The last observation suggests that, although good readers in the first grade may be capable of forming internal representations of text at a letter or word level, they do not make use of the syntactic-semantic constraints provided by the prose passage to form internal representations of text at phrase level or above.

All fifth graders tended to miss a disproportionate number of $t \mathrm{~s}$ in the word the in both the prose and the scrambled-word passages. Conditional error percentages significantly above chance level were obtained for both good $[\mathrm{t}(12)=21.3, \mathrm{p}<.01]$ and poor readers $[\mathrm{t}(14)=5.62, \mathrm{p}<.01]$ on the prose passage, and for both good $[\mathrm{t}(12)=4.44, \mathrm{p}<.01]$ and poor readers $[t(12)=2.23, p<.05]$ on the scrambled-word passage. In contrast, the conditional error percentages for the scrambled-letter and the list passages were at chance level for both groups of readers, except that poor readers performed significantly above chance level on the scrambled-letter passage $[\mathrm{t}(5)=2.95, \mathrm{p}<.05]$. This result, however, is based only on 6 subjects who made errors on this passage, the remaining 16 having made no errors at all.

All fifth graders, in contrast to first graders, showed higher conditional error percentages on the prose than on the scrambled-word passage. This difference was significant for good readers $[\mathrm{t}(24)=2.53$, $p<.05]$ and marginal for poor readers $[t(25)=1.79$, $.10>\mathrm{p}>.05]$. Since the reading grade equivalents of good readers in the fifth grade were substantially above those of poor readers (good, 7.8; poor, 4.2), these data are consistent with the notion that processing levels necessary for skilled reading become consolidated by that stage. Good readers in the fifth grade are thus deemed to be fully skilled in phrase-level processing, whereas poor readers in the fifth grade are not.

\section{DISCUSSION}

The observed pattern of detection errors on the word the depends not only on the structure of the search passage in which the is embedded, but also on the attained level of the subjects' reading ability. All subjects make an equivalent proportion of conditional errors on the word the in passages whose structure precludes normal reading. The conditional error percentages for the scrambled-word and list passages were at or below the expected chance level of $33 \%$. In contrast, the conditional error percentages obtained with the prose and the scrambled-word passages were above chance level and were directly dependent on the subjects' attained degree of reading skill. Children whose reading grade equivalent was 1 or below showed conditional percentages of errors at the locations that were not significantly different from those expected on the basis of chance. More fluent readers and adults 
showed conditional error percentages significantly above chance level, indicating that a preponderance of detection errors was made on the word the. The difference in conditional error percentages between the prose and the scrambled-word passages was significant only for readers in school Grades 4 and 5 and for adults, indicating that the conditional error performance of only the most fluent readers is influenced by the syntactic-semantic constraints of the search passage.

These data are consistent with levels-of-processing models of reading as advocated by Drewnowski and Healy (1977), Doehring (1976), and Gibson (1971). In particular, the subjects' performance on the scrambled-letter passage, where the assumed highest level of processing is that of the letter or letter group, is consistent with the notion of letter-by-letter scanning that is largely independent of the subjects' reading ability. Similarly, because the normal left-to-right reading pattern is eliminated when the search passage is presented in the form of a vertical word list, with all the words being typed flush left, the subjects' performance on the list passage is again assumed to be largely independent of the degree of reading skill. All subjects thus seem to be equally capable of identifying the target letter $t$ in passages whose structure precludes normal reading.

A different pattern of data is observed for passages whose structure does permit the formation of higher level reading-processing units. Only the performance of children reading at Grade 1 level is now consistent with the hypothesis that they continue to employ letter-by-letter scanning when dealing with the prose or the scrambled-word passages. The preponderance of errors on the word the that is made on these passages by the more skilled readers supports the hypothesis that skilled readers tend to process the prose and scrambled-word passages in terms of phrase-level or word-level units. Because the highest level of processing the prose passage is assumed to be the phrase level or higher, whereas the highest level of processing permitted by the structure of the scrambled-word passage is assumed to be the level of the word or the word group, differences in conditional error percentages between the two passages are expected and obtained only for the most fluent readers, assumed to be most sensitive to the syntactic-semantic constraints of the search passage. However, it is puzzling that this separation in conditional error percentages is achieved by a drop in the proportion of the errors with school grade on the scrambled-word passage with no change on the prose passage, whereas one might have expected the conditional error percentage for the scrambled-word passage to remain constant and that for the prose passage to increase with reading ability. A possible explanation for the present result may be that fluent readers and adults, who are most sensitive to the constraints of the search passage, are disturbed the most by the ungrammaticality of the scrambled-word passage and tend to scan it more slowly and more carefully.

The combined effects of passage structure and reading ability thus tend to support the hypothesis that learning to read involves the acquisition of reading-processing skills at various levels and indicate that this acquisition follows a specific time course, with lower level skills being acquired and consolidated before higher level skills are fully developed. The present data place the acquisition of word-level processing (at least for the most frequent word, the) at first-grade level, with this type of processing becoming fully functional by secondgrade level. On the other hand, syntactic-semantic skills, thought to be necessary for rapid reading at phrase-level or higher, do not begin to appear until some years later, becoming fully functional by fifth-grade level.

These data provide support for the multilevel model of reading put forward by Drewnowski and Healy (1977). It is proposed that subjects tend to form internal representations of text at the highest level that is available to them, in parallel with processing at lower levels. The highest available level of processing is now thought to be determined in the first instance by the subjects' attained degree of reading skill, and in the second instance, by the structure of the search passage. It is further proposed that the highest level of the internal representation of text is determined by syntactic-semantic constraints and by the familiarity of the material. Thus, with fluent readers, capable of forming internal representations of text at the highest syntactic-semantic level, the structure of the search passage is thought to be limiting, with the pattern of detection errors on the word the being determined largely by the syntactic-semantic constraints of the search passage, and with a greater proportion of detection errors on the word the being expected with more highly constrained passages. Less fluent and beginning readers are deemed incapable of taking advantage of the additional information provided by the more highly constrained passages, and since the attained degree of reading skill is then limiting, such readers are not expected to show changes in their conditional error percentages with increasing syntacticsemantic constraints of the search passage. In terms of the Drewnowski and Healy (1977) model, the conditional error percentage thus serves as an index of whether the subject's optimal level of processing text is above or below that dictated by the structure of the search passage.

The changing pattern of data with reading grade is thus best explained by the underlying development of the subjects' reading skill. Alternative explanations are incompatible with the present pattern of results. For example, the notion that the letter-detection task employed here may require a type of processing incompatible with normal reading, so that the more similar the search passage is to English text, the more 
incompatibility might exist between reading and detection tasks, resulting in more detection errors, does not account for the fact that a preponderance of the detection errors occur on the word the. Furthermore, this notion does not account for the specific dependence of the conditional error percentages on the subjects' reading skill, particularly since all subjects are assumed to be equally competent on the detection task, as indicated by their uniformly accurate performance on the list and the scrambled-letter passages. The data cannot be explained, moreover, by the varying degrees of the subjects' attentiveness to the task, or by the notion of a speed-accuracy tradeoff, since the principal dependent variable employed here, the conditional error percentage, is deemed to be independent of these factors.

Drewnowski and Healy (1977) have argued, moreover, that the observed pattern of letter-detection errors on the words the and and is not a specific property of these words, but that it reflects the properties of a more general reading mechanism. Indeed, the observed effect does not seem to be solely due to any simple property of the word per se, such as word frequency, because the proportion of detection errors on the word the is eliminated or diminished when the search passage is presented in the form of a vertical word list, or when the word the is placed in an inappropriate context, as in the scrambled-word passage. Rather, the critical property of the word the is that it is more likely than other words to enter into the highest level reading units available in any given search passage. And because highly frequent words are thought to be most likely to be read in terms of units larger than letters, and highly frequent phrases or word frames are thought to be most likely to be read in terms of units larger than words, it follows that the word the will always be read at the highest level available. Placing the word the in a frequent phrase or word frame (e.g., "on the ") should thus increase the proportion of detection errors, while embedding the trigram the in a less frequent target word (e.g., "brother") should decrease the proportion of detection errors, provided, of course, that the subjects' attained degree of reading skill allows them to be sensitive to changes in passage structure and to task demands.

Because the observed pattern of conditional error percentage scores is found to depend on the subjects' reading ability, the present letter-detection paradigm might be expected to serve as a diagnostic measure of reading skill. As previously noted by Drewnowski and Healy (1977), the present task approaches the normal reading situations more closely than do many of the other letter-detection paradigms described in the literature (e.g., Johnson, 1975; Wheeler, 1970). And because the task specifically measures the levels of processing that an individual has mastered and is utilizing in processing a given text, the pattern of performance on this task would be expected to provide more theoretical insight into the acquisition of reading skills in learning to read than would the conventionally employed model-independent reading tests.

\section{Appendix}

Prose: The boys' mother washed their clothes the other day. There was soap on the floor. Then John's brother slipped on the slick lather and fell.

Scrambled The was mother floor their clothes the other and. Word: There slick on day the fell. Then washed brother soap boys' the on lather John's slipped.

Scrambled Tbo hemw' sotred ysaher thieh dretaos tlc yteoh Letter: hee. Trheh foo heoo pu tsa wlasr. Tbre holn's hnotsip Jnhedep ro tes kclha dntell lia fher.

List:

$\begin{array}{llll}\text { The } & \text { the } & \text { day } & \text { soap } \\ \text { was } & \text { other } & \text { the } & \text { boys' } \\ \text { mother } & \text { and } & \text { fell } & \text { the } \\ \text { floor } & \text { There } & \text { Then } & \text { on } \\ \text { their } & \text { slick } & \text { washed } & \text { lather } \\ \text { clothes } & \text { on } & \text { brother } & \begin{array}{l}\text { John's } \\ \text { slipped }\end{array}\end{array}$

Question: Why did John's brother fall?

\section{REFERENCES}

Corcoran, D. W. J. An acoustic factor in letter cancellation. Nature, 1966, 210, 658.

Doehring, D. G. Acquisition of rapid reading responses. Monograph of the Society for Research in Child Development, 1976, 41, 1-54.

DREWNowsKI, A., \& Healy. A. F. Detection errors on the and and: Evidence for reading units larger than the word. Memory \& Cognition, 1977, 5, 636-647.

Gibson, E. J. Perceptual learning and the theory of word perception. Cognitive Psychology, 1971, 2, 357-368.

Healy. A. F. Detection errors on the word the: Evidence for reading units larger than letters. Journal of Experimental Psychology: Human Perception and Performance, 1976 , 2, $235-242$.

JoHnson. N. F. On the function of letters in word identification: Some data and a preliminary model. Journal of Verbal Learning and Verbal Behavior, 1975, 14, 17-29.

LaBerge, D., \& Samuels. S. J. Toward a theory of automatic information processing. Cognitive Psychology, 1974, 6. 293-323.

Мон AN, P. J. Acoustic factors in letter cancellation: Developmental considerations. Developmental Psychology, 1978, 14. 117.118 .

SмIтн, F. Understanding reading: A psycholinguistic analysis of reading and learning to read. New York: Holt, Rinehart, $\&$ Winston. 1971.

Smith, F. (Ed.). Psycholinguistics and reading. New York: Holt. Rinehart. \& Winston. 1973

WheEler. D. D. Processes in word recognition. Cognitive Psychology. 1970. 1. 59-85.

(Received for publication January 23, 1978; revision accepted May 30. 1978.) 